\title{
GLOBALIZAÇÃO E AS CIÊNCIAS SOCIAIS ANOTAÇÕES SOBRE OS DESAFIOS APRESENTADOS PELA ASCENSÃO DOS PAÍSES BRICS ${ }^{1}$
}

\author{
Tom Dwyer*
}

\begin{abstract}
Resumo: A globalização e as transformações do papel do Brasil no mundo desafiam a sociologiabrasileira.Novasquestõeseatoresemergem, enovostemasdepesquisaeensino se impõem de tal forma que países que antes pareciam irrelevantes ao desenvolvimento brasileiro, com destaque para a China, desafiam nossa imaginação sociológica. É preciso compreender as relações se constroem com nossos parceiros dos BRICS e, na medida em que o conhecemos melhor, também aprender com eles.
\end{abstract}

Palavras-chave: Globalização; sociologia brasileira; BRICS; China.

Abstract: This article confronts some recent challenges to Brazilian sociology as it faces issues imposed by globalization and the transformation of Brazil's role in the world. New questions and actors arrive on the scene, and new research and teaching topics impose themselves. Countries that once seemed irrelevant to Brazil's development, especially China, present challenge for our sociological imagination. It is necessary to seek to understand our emerging relations with our BRICS partners, and in getting to know them better, learn from them.

Keywords: Globalization; Brazilian sociology; BRICS; China.

* Professor titular de Sociologia no Instituto de Filosofia e Ciências Humanas da Universidade Estadual de Campinas (UNICAMP) - Campinas, São Paulo, Brasil. Email: tomdwyer@terra.com.br.

${ }^{1} \mathrm{O}$ artigo é uma condensação de reflexões originalmente elaboradas em palestras e textos impressos ao longo dos últimos anos. Além dos textos na minha bibliografia, este texto é baseado em um texto introdutório (inédito) a dois livros da ANPOCS sobre os Brics e a seguinte série de reflexões; 2012. Dwyer, Tom. A China e o Brasil Mudanças e Permanências e Desafios para a Sociologia Brasileira, em: Mudanças e Desafios, Scalon, C., Rasia, J. M. e Sallas, A. L. (orgs). Rio de Janeiro, 7 Letras 


\section{Introdução}

Octavio Ianni escreveu, sobre as teorias da globalização:

[...] cabe reconhecer que várias dentre elas continuam a conferir um papel relevante ao Estado-nação. Estão nesse caso: a interdependência das nações, o mundo sistêmico, a modernização do mundo e a aldeia global. Concebem o mundo como um todo composto de nações interdependentes, desiguais, reciprocamente referidas, polarizadas e lideradas pelas mais fortes, dominantes, avançadas, civilizadas, européias ou ocidentais (IANNI, 1997: 20).

Quando Ianni começou a refletir sobre a globalização, ele mal imaginava uma mudança da ordem mundial onde quatro grandes países em desenvolvimento passariam a ser vistos, sobretudo depois de uma grave crise financeira nos países desenvolvidos, como um novo eixo possível da economia mundial, nos termos da conceptualização elaborada por Jim O’Neill do banco Goldman Sachs em 2001.

Ou seja, uma vez mais, segundo Ianni:

a sociologia está ingressando na época do globalismo. Os desafios criados com a formação da sociedade global não só representam uma nova realidade como também criam novos desafios metodológicos e teóricos.

e Sociedade Brasileira de Sociologia. ISBN 978-85-7577-988-0 pp. 179-202; 2011. Dwyer, Tom. 'Relations between the BRICS: AReflection from a Brazilian Sociological Viewpoint.' Fudan Journal of the Humanities and Social Sciences. Vol. 4, no. 4, pp. 27-55; 2011. Dwyer, Tom. A China e os Desafios das Ciências Sociais Brasileiras no Cenário do Mundo em Processo de Globalização. In Ribeiro, G. L. et ali. (orgs) "As Ciências Sociais no Mundo Contemporâneo: Revisões e prospecções” Brasília, Letras Livres e Editora da UnB. pp. 211-224; 2010. Dwyer, Tom. Jinzhuansiguo' Shehuixue Zouxiang Shijie. (BRICs' Sociology to the world) in "Chinese Social Sciences Today" (http://sspress.cass.cn/paper/10195.htm). 
Até mesmo alguns dos fundamentos epistemológicos da sociologia podem ser repensados ou inovados, quando a reflexão se depara com as configurações e os movimentos da sociedade global. Neste sentido é que o globalismo se constitui no novo emblema da sociologia (IANNI, 1997: 15-16).

Anos mais tarde, Michael Burawoy, atual presidente da Associação Internacional de Sociologia (ISA) escreveu:

as markets become global so sociology aspires to become global too, contributing to a global civil society, knitting together communities, organizations and movements across national boundaries... global sociologies are laboriously constituted from below out of particular national sociologies.... Building a global sociology from below is a daunting and precarious task. (Burawoy, 2010, 25)

Devido à globalização e à transformação do papel do Brasil no mundo, novos fatores externos já estão transformando a Sociologia brasileira. Novos interlocutores estão chegando, novos problemas, e novos temas de ensino e de pesquisa se apresentam. Países que pareciam ser totalmente irrelevantes para nosso desenvolvimento, agora passam a ser percebidos por muitos como altamente relevantes. Com isto, surge o desafio de desenvolver uma compreensão a respeito de nossas possíveis relações com nossos parceiros nos BRICS, e também de ver o que podemos apreender com eles. Até recentemente, muito poucos no Brasil perceberam que a ascensão da China teria profundas repercussões sobre o país; no começo, esta visão era compartilhada por diplomatas e homens de negócios sobretudo. Esses atores não tiveram nem a força, nem a capacidade de aumentar o grau de consciência geral sobre este fato. As ciências sociais também demoravam para reconhecer o papel da China e dos países BRICS. 


\section{Notas sobre os diálogos iniciais entre os BRICS}

É sempre bom relembrar, ao abrir um novo campo de reflexão, que há alguns esforços pioneiros com os quais podemos aprender. Uma parte do premiado Paradigmas do capitalismo agrário em questão (ABRAMOVAY, 1992), foi inspirado no grande estudioso russo da agricultura Alexander Chayanov. O trabalho deste autor permitiu a Abramovay desenvolver uma reflexão inovadora sobre o papel do pequeno agricultor. Uma agricultura capitalista seria capaz de fornecer muitos produtos que as operações em grande escala, dirigidas a mercados de massa ou exportação, não podem fornecer a mercados urbanos. Ou seja, milhões de pequenos agricultores não seriam mais condenados a desaparecer frente ao poder avassalador do avanço do capitalismo agrícola, mas, com os estímulos apropriados, poderiam ter um papel importante na sociedade e na economia como um todo. Quase duas décadas depois, um primeiro livro de Ciências Sociais sobre as relações Brasil-Rússia foi organizado por Alexandre Zhebit (2009), da UFRJ. "O conhecimento da cultura aproxima os povos, cria uma base sem a qual é impossível realizar a parceria duradora na esfera política e econômica" (TYURDENEV, 2009: vii).

Os sociólogos indianos têm sido tradicionalmente pouco lidos entre nós, embora na Índia os escritos sobre desenvolvimento de Octavio Ianni, Fernando Henrique Cardoso e Celso Furtado sejam conhecidos. Assim como a pedagogia dos oprimidos, de Paulo Freyre. Na história do Brasil, o livro A Bahia e a Carreira da Índia, de Amaral Lapa (1968), é um exemplo de um trabalho pioneiro que nos permite repensar os laços históricos do Brasil com a Índia. Um primeiro livro de Ciências Sociais foi editado em 2003, intitulado Diálogos Tropicais - Brasil e Índia no Brasil, os organizadores estão numa busca de quebrar a "dependência quase crônica - marcada pela colonialidade do poder - das percepções acadêmicas recíprocas, com relação aos espelhos europeus e norte-americanos (teorias, bibliografia e línguas)" que demarca a distância entre os dois países (LOUNDO; MISSE, 2003: 11-12). 
Em tempos mais recentes, os estudos pós-coloniais têm trazido referências indianas às ciências sociais. Intelectuais indianos passaram a participar mais em congressos e publicações brasileiros; em 2005, por exemplo, Sujata Patel (2006) participou no congresso da SBS em Belo Horizonte.

Os textos pioneiros da coletânea dos escritos de Gilberto Freyre (2003), China Tropical, e o magnifico livro A China no Brasil, de José Roberto Teixeira Leite (1999), traçam caminhos inovadores para a reinterpretação da história das relações entre a China e o Brasil. No sentido de Hobsbawm: "localizar as raízes de nosso presente no solo do passado, e talvez sobretudo, ver o passado como um todos coerente e não [...] como uma montagem de tópicos isolados: a história de diferentes estados, da política, da economia, da cultura ou outros" (LEITE, 1999: 8). Teixeira Leite (1999: 11) observou, com muita propriedade na época, que "o nome China há de, por certo, suscitar noções confusas e de qualquer modo significar muito pouco a 99,99\% de nós brasileiros, acostumados a associá-lo a um país nebuloso, tão desconhecido e quase tão remotos quanto Marte ou a Lua". No livro A China no Brasil, o autor busca demostrar que, além de "aborígene, lusitano... africano, indiano", o Brasil também foi um país construído sob influência chinesa "em numerosos usos e costumes, em certos requintes da civilização material, em pormenores de arquitetura e artísticos; chinês enfim em muitas formas de pensar, viver, agir e sentir" (LEITE, 1999: 11).

Foi necessário esperar mais uma década para ver a publicação de livros oriundos das ciências sociais tratando das relações Brasil- China. "A China já está restaurada como o centro econômico dos mais relevantes do mundo. Logo, influenciará de forma enorme a economia e a sociedade da América Latina. [...] Dado o contexto, é importante melhorar nosso entendimento sobre as dimensões sócio-políticas e ambientais da expansão da China" escreveram os organizadores (FERREIRA; ALBUQUERQUE, 2013: 10). Outros livros relevantes são sobre a parceria estratégica entre os dois países (BIATO, 2010) e a coletânea Brasil-China organizado pelo Prof. Zhebit (2013), cujo subtítulo é "construindo os BRICS". 


\section{Construindo uma sociologia dos e nos BRICS}

Em Abril de 2010, na ocasião da celebração dos 40 anos do Instituto de Sociologia da Chinese Academy of Social Sciences (CASS), Li Peilin organizou uma discussão entre os presidentes e ex-presidentes das associações nacionais de sociologia dos países BRIC. O intuito de Li Peilin, diretor do instituto, era averiguar se, de fato, fazia sentido incentivar um intercâmbio acadêmico da China com o Brasil e com a Índia, para complementar o já existente entre Rússia e China.

Nesse encontro na CASS, o Brasil foi representado por dois ex-presidentes da SBS. José Vicente Tavares dos Santos e o autor deste artigo. Na ocasião, apresentei um paper no qual eu sugeria quatro direções para a pesquisa em ciências sociais sobre os países BRIC: (1) mapeamento, documentação e análise teórica dos conflitos entre os países BRIC e seus cidadãos; (2) a produção de uma análise comparativa dos diversos processos de desenvolvimento dos países BRIC; (3) mudanças nas perspectivas, valores e horizontes da juventude, assim como na visão dos jovens sobre os outros países BRIC, o que inclui a capacidade de absorver os signos e elementos da cultura desses países; e (4) reescrever a história.

Estas discussões têm levado a uma abordagem fértil, o que denomino Sociologia nos BRICS, onde se examinam processos sociais nas suas dimensões diacrónicas e sincrónicas em cada um dos países BRICS no intuito de produzir compreensões comparativas, e, ao mesmo tempo, de aprofundar nosso conhecimento e nossa capacidade de construir hipóteses de trabalho. Importa lembrar que, juntos, estes quatro países representam quase a metade da população mundial! O fato da África do Sul ter sido admitida mais tarde no clube adicionou ao significado econômico atribuído pelo fundador do conceito, Jim O’Neill, um sentido político e geográfico. Com a inclusão desse novo país fica mais difícil fazer generalizações, e aumenta bastante a complexidade do trabalho comparativo. 


\section{Sociologia dos BRICS}

Do meu ponto de vista, estamos envolvidos em um diálogo científico que requer um alto grau de elaboração e compreensão; ao fazer isso, examinamos as palavras dos outros e buscamos construir uma relação juntos. E o próprio processo de construção desse diálogo é, ele mesmo, um objeto interessante de análise, por ser parte crucial na formação dos BRICS enquanto bloco político. A questão da comunicação é crucial no meu próprio trabalho de desenvolver uma sociologia dos BRICS. Minha percepção resulta de três tipos de atividades: (1) visitas constantes à China, conduzindo pesquisas em colaboração com colegas chineses, assim como recebendo delegações chinesas na minha universidade; (2) participação de diálogos internacionais patrocinados pela ISA, assim como de iniciativas relacionadas aos BRICS em congressos no Brasil, na Índia, na Rússia e na China; (3) a observação de fiascos administrativos ou políticos, os quais muitas vezes refletem diferenças mais profundas.

\section{Conflitos e fiascos}

Em Novembro de 2012, na cidade de São Paulo ${ }^{1}$, mais de quatrocentas pessoas se reuniram no Parlatino do Memoria da América Latina - entre eles, duzentos representantes de mais de quarenta universidades chinesas, convidados a participar de uma feira educacional. Uma das iscas foi o fato de que estas instituições poderiam recrutar até cinco mil estudantes brasileiros dentro do programa "Ciências Sem Fronteiras". A sessão de abertura estava repleta de oficiais do governo brasileiro, e ouvimos discursos sobre a importância das relações entre Brasil e China. O então ministro da Educação, Aloísio Mercadante, afirmou

\footnotetext{
${ }^{2}$ Disponível em: http://portal.mec.gov.br/index.php?option=com_content\&vie $\mathrm{w}=$ article\&id=18245:brasil-e-china-intensificam-relacao-na-area-educacional\&catid=221. Acesso em: 3 mai. 2014.
} 
que a educação era a principal ponte da diplomacia, e enfatizou a necessidade de consolidarmos uma parceria histórica com a China: "É fundamental o intercâmbio acadêmico e cultural de estudantes, tanto os daqui como os vindos de lá, de maneira tão estratégica como nas parcerias que já mantemos com os chineses no ramo da nanotecnologia, na agricultura, na inovação".

Neste mesmo dia, enquanto eu caminhava pelos estandes, não havia um só estudante brasileiro! Na manhã seguinte, um de nossos assistentes de pesquisa da Unicamp percorreu o mesmo caminho e fez a mesma observação. Os educadores chineses, oriundos de um país em desenvolvimento ainda pobre, sobrevoaram meio mundo para encontrar estudantes em potencial, não entendiam o que se passava, e buscavam explicações! Senti-me extremamente constrangido.

Atualmente, apenas cento e noventa e três estudantes brasileiros foram contemplados com bolsas de estudo pelo programa Ciência sem Fronteiras para estudar na China². A oferta de 5.000 bolsas a alunos brasileiros foi baseada em qual critério? Qual diálogo com as universidades foi criado pelo governo brasileiro para garantir o cumprimento deste objetivo?

Os dois outros conflitos ocorreram na esfera de relações internacionais. Na ocasião da visita do Presidente Hu Jintao ao Brasil, em 2004, o Presidente Lula declarou oficialmente que reconheceria a China como um país de economia de mercado na Organização Mundial de Comércio $^{3}$. Essa promessa foi

${ }^{3}$ Disponível em: http://www.cienciasemfronteiras.gov.br/web/csf/bolsistaspelo-mundo?p_p_id=mapabolsistasportlet_WAR_mapabolsistasportlet_ INSTANCE_Y7eO\&p_p_lifecy cle $=0 \& p_{-}$_p_state $=$normal \& mode=view\&p_p_col_id=column2\&p_p_col_. Acesso em: 3 mai. 2014. Do total de 50,175 bolsas concedidas, somente 12 brasileiros estão na África do Sul, 4 na Rússia e 5 na Índia! 
bombardeada no Brasil pela FIESP ${ }^{4}$. Desde então, "a frustração com o descumprimento do acordo foi um dos motivos do relativo esfriamento das relações sino-brasileiras, após um começo animado no governo Lula"; em uma entrevista coletiva, o diretor do departamento da América Latina do Ministério das Relações Exteriores da China, Yang Wanming, alertou que, "as palavras de Lula em 2004 se transformaram em letras mortas"5.

Certamente, o diálogo e o entendimento entre as partes se tornam mais difíceis ao examinarmos desastres que poderiam ser evitados, como nos casos do Ministro da Educação e do Presidente do Brasil. Se o então ministro Aloísio Mercadante fosse mais cauteloso, e menos fanfarrão, ele certamente teria feito uma contribuição muito mais construtiva para o intercambio universitário, assim como para a construção de um diálogo mais sólido com um parceiro dos BRICS.

Um outro exemplo de um fiasco diplomático ocorreu quando a China e a Rússia decidiram não apoiar as pretensões brasileiras, indianas e de outros relativas à obtenção de um assento permanente no Conselho de Segurança das Nações Unidas (ONU). Esta decisão foi uma grande decepção para o governo brasileiro e, ao que consta, poderia ter sido evitada. O Brasil se aliou à Índia, ao Japão e à Alemanha para reivindicar o assento no Conselho de Segurança. Porém, sabemos hoje, a China enxerga a eventual admissão do Japão como uma humilhação, inclusive com possíveis repercussões para sua ordem interna. Teríamos que perguntar se não foi uma falta de preparo que levou o governo brasileiro a investimentos diplomáticos fadados ao fracasso?

\footnotetext{
4 Disponível em: http://www.bbc.co.uk/portuguese/reporterbbc/story/ 2004/11/041112_jintao.shtml. Disponível em: http://oglobo.globo.com/ economia/presidente-chines-deve-cobrar-de-lula-reconhecimento-do-paisasiatico-como-economia-de-mercado-3156076. Acesso em: 30 mai. 2014.

5 Disponível em: http://joaocarlos.net.br/2011/07/china-cobra-do-brasilreconhecimento-como-economia-de-mercado/\#sthash.SpP2dUS4.dpuf. Acesso em: 30 mai. 2014.
} 
O importante é tirar lições destes três desastres que solapam a confiança mútua e tentar evitar incidentes graves no futuro, assim contribuindo para construir relações mais sólidas.

\section{Estudar a globalização}

Para ser útil e operacionalizável, parece-me necessário fazer referência a uma definição restrita e científica do conceito globalização. Boaventura de Souza Santos (2005: 89) se aproxima de uma definição simples ao escrever: "O sistema mundial em transição é muito complexo porque constituído por três grandes constelações de práticas - práticas interestatais, práticas capitalistas globais e práticas sociais e culturais transnacionais profundamente entrelaçadas segundo dinâmicas indeterminadas". Michel Wieviorka (2008) desenvolveu uma ideia ainda mais simples, porém de grande alcance, ao fixar seu olhar em três processos que ele conceituou como sendo relativamente autônomos uns dos outros: (1) comércio, (2) relações supranacionais, (3) trocas de informação. Todos envolvem "uma intensificação das relações sociais em escala mundial, que ligam localidades distantes de tal maneira que acontecimentos locais são modelados por eventos ocorrendo a muitas milhas de distância e vice-versa" (GIDDENS, 1991: 69).

\section{Sociologia dos BRICS}

Ianni sugeriu que era possível analisar a globalização a partir de óticas fornecidas pelas escolas clássicas da Sociologia: funcionalismo, marxismo e teoria weberiana. No resto desta seção, tratarei dados que reflitam as mudanças nas funções de um regime económico e as interações dos cidadãos e organizações na medida em que constroem os BRICS, o primeiro funcionalista, o segundo mais próximo de um espírito Weberiano. 


\section{Comércio}

Para muitos, o aumento dos fluxos comerciais são a mola propulsora da globalização, para mim esse é apenas um dos fatores, porém o mais comentado. Uma sociologia dos BRICS propõe-se a estudar as relações comerciais entre os países, e eventualmente os conflitos associados a estas relações.

Entre 1990 e 2010 o comércio FOB bilateral do Brasil com o mundo aumentou $637 \%$ em dólares americanos. Porém, o comércio com os países BRICS aumentou mais: $735 \%$ com a África do Sul, $10.132 \%$ com a China, $4.104 \%$ com Índia e $1.297 \%$ com a Rússia (após 1993). Esses crescentes fluxos comerciais entre os países são o ponto do iceberg do fenômeno BRICS. Em 2009, o aumento na demanda indiana por açúcar e álcool aumentou os preços no Brasil. Em 2010, a China teve um impacto muito forte sobre o preço do aço brasileiro. Ainda nesse mesmo ano, a China representava quase 15\% de comércio exterior bi-lateral brasileiro (DWYER, 2011: 37-8).

A dimensão comercial é a melhor estudada das três dimensões da globalização. Na sua teoria dos "sistemas mundiais", Wallerstein postula que a antiga relação "centro - semiperiferia periferia" não seria eterna na economia global. Hoje, assistimos a ascensão da China e devemos voltar a Arrighi (2008) para compreender o que está em jogo. Há uma enorme mudança no fluxo de comércio mundial em que a China assume um lugar central e se especializa na manufatura dos mais diversos produtos. Em outros textos já apontei que um dos resultados dessa mudança rápida é que existe uma agenda brasileira em relação aos países BRICS: a) como competir? (em alguns casos, sobretudo relacionados à China, liderados por segmentos da FIESP, como barrar?); b) como cooperar e reunir forças com os chineses?

Embora essas perguntas não se limitem à China, o país é hoje alvo de grandes preocupações no Brasil. A resposta à primeira pergunta leva a uma agenda de proteção (proposta por segmentos da Federação das Indústrias do Estado de São Paulo (FIESP)), de inovação (Embrapa, Coteminas), de educação a de 
desenvolvimento. Essas questões estão sendo estudadas em diversas universidades, incluindo a Unicamp, UFRGS, FAAP, UFRJ, e no IPEA. Os embaixadores chineses entrevistados por Biato Jr. (2010) sempre bateram na mesma tecla: o Brasil precisa inovar para poder competir com a China.

Alguns setores exportadores de produtos manufaturados brasileiros batem em outra tecla: é preciso reduzir o custo Brasil, melhorar a infraestrutura, reduzir impostos em cascata, reduzir os custos e as incertezas associadas às leis trabalhistas etc. Ontem a redução as taxas de câmbio e de juros estavam sendo citadas como medidas necessárias para colocar o país em melhores condições de competir, hoje a falta infraestrutura, a excessiva burocratização, a falta de confiança e a necessidade de uma abertura econômica. Durante uma pesquisa de campo em Xangai em junho de 2011 entrevistados brasileiros relataram que havia conflitos em potencial em torno da estratégia de defesa comercial do país. Entendo que as solicitações de salvaguardas feitas na Organização Mundial de Comércio (OMC) por industriais brasileiros (algo que envolve apenas $10 \%$ de todas nossas importações da China) não enfrentam resistência chinesa. O governo Chinês entende que nossas indústrias precisam de tempo para se ajustar, para se tornarem competitivas. Porém as salvaguardas são por tempo limitado. Em alguns casos, nossos capitalistas imaginam que as regras da OMC são "para inglês ver" e que podem esticá-las ad infinitum, o que não é o caso.

Vemos conflitos não apenas entre os representantes de interesses brasileiros e chineses e, em menor grau, com os outros BRICS, mas também entre frações dos capitalistas brasileiros. Um conflito típico e bastante visível colocava em oposição a indústria envolvida na manufatura doméstica de sapatos a outros segmentos da mesma indústria que usam componentes importados. Nesse contexto, emergem novas articulações entre atores sociais. Por exemplo, o Conselho Empresarial Brasil-China é um contrapeso a grupos que se opõem à crescente presença de produtos manufaturados chineses em terras brasileiras. 
Também existem esforços de cooperação com os parceiros dos BRICS que são visíveis na busca por joint ventures, por investimentos, e nas tentativas de acrescentar valor aos produtos hoje exportados como commodities. Embraer, Petrobrás, Vale, Inbrew, Marcopolo, Weg, Embraco são algumas dentre as empresas de capital brasileiro ativas em grandes países em desenvolvimento, empresas da China, Rússia, Índia e África do Sul também atuem em economias emergentes, inclusive no Brasil Nas faculdades de administração, começa-se a estudar casos de êxito e de fracasso nestes mercados e também há oferta de cursos de língua.

Hoje, no Brasil a desindustrialização se generalizou, a mineração e o agribusiness se fortaleceram mas não parece existir uma visão amplamente compartilhada sobre o futuro. Uma coisa é certa, o país terá que abandonar sua pretensão de ser um país industrial que "produz tudo" e fazer um esforço de pesquisa e inovação para descobrir as áreas (fora a área agrícola e a mineração) nas quais tem vantagens comparativas na economia mundial se quisermos continuar a ser um país com um setor industrial de peso. $\mathrm{O}$ fracasso das políticas industriais destes últimos anos torna urgente esta discussão. No século XXI, teremos que desenvolver uma nova visão e novos produtos, não apenas em relação à China e aos outros parceiros BRICS, mas também em relação ao mundo.

\section{Relações supranacionais}

Deng Xiaoping disse que "assim como não poderá haver o século do Pacífico sem a China, não poderá haver o século da América Latina sem o Brasil". Na visão do diplomata Oswaldo Biato Jr., "para a China, a aproximação com o Brasil sempre foi almejada pela importância do Brasil dentro da América Latina, onde representa, dadas as dimensões físicas, de sua economia e população, às quais se agrega um relativo avanço tecnológico, o maior e mais avançado país da região" (BIATO, 2010: 17). 
A partir de 2009, uma iniciativa mais ambiciosa foi lançada os Fóruns dos líderes dos BRICS. A Declaração de Sanya ${ }^{6}$, produto do fórum de 2011, merece a atenção de todos. A depender de seus desdobramentos em atividades práticas, a Declaração ocupará a atenção de especialistas em Relações Internacionais e, espero, em Sociologia. O documento é claro ao apontar o desenvolvimento de iniciativas de cunho político e social.

Ao empregar a palavra "supranacional" estou indicando uma área de atuação que vai além das tradicionais "relações internacionais", incluindo certos "práticas interestatais" (SANTOS, 2005) que permite incluir outras relações de poder entre organizações que se articulem na esfera internacional. Vou mencionar três tipos:

1. Cooperação internacional entre ONGs, tais como, Human Rights Watch, Greenpeace, Anistia Internacional, Transparência Internacional, entre outras. Aqui, todo um espaço se abre, onde atores não governamentais buscam suprir as deficiências da ação dos Estados-nação. Os papeis destes órgãos variam conforme o país: na China, sua singularidade é a de serem auxiliares do Partido-Estado, tendo, por isso, pouca autonomia de ação, enquanto na Índia, Rússia e África do Sul sua autonomia é maior. Convém mencionar que a SBS e as associações científicas nacionais de Sociologia da China, Rússia, Índia e África do Sul desenvolvem relações de cooperação desde 2010. Um primeiro livro, sobre estratificação social nos países BRIC, foi lançado em mandarim em Pequim (LI et al, 2011) e em inglês, em Cingapura (LI et al, 2013). Um segundo livro, sobre "sociologia da juventude nos países BRIC" deve ser lançado em inglês no decorrer do ano de 2015.

2. Não podemos fechar nossos olhos às organizações supranacionais clandestinas, que se especializam no tráfico de drogas, no contrabando e na espionagem industrial. Pareceme uma hipótese plausível a de que, com o aumento geral dos

\footnotetext{
${ }^{6}$ Disponível em: www.itamaraty.gov.br/temas-mais-informacoes/saiba-maisbric/documentos-emitidos-pelos-chefes-de-estado-e-de/sanya-declaration-iiibrics-summit/view.
} 
contatos entre o Brasil e os países BRICS, haverá uma crescente atuação dessas organizações. Depois da prisão do "maior contrabandista" do Brasil, Lao King Chong, duas tríades chinesas começaram a enviar suas equipes da China para "intimidar, ameaçar, assaltar, e se necessário matar qualquer um que deixar de pagar a propina de proteção ou quem tenta impedir sua atuação" (GLENNY, 2009: 283). Um outro tipo de crime internacional acontece na internet. Os fabricantes dos programas antivírus Norton patrocinaram um survey em quatorze países com mais de sete mil usuários de internet, $65 \%$ do total dos entrevistados tinham sido vítimas de um tipo ou outro de cibercrime: enquanto a porcentagem de vítimas de vírus ou malware nos EUA era de $73 \%$, na China alcançava os $83 \%$ e, no Brasil e na Índia, 76\% (NCR, 2010). Em 2007, a Forbes considerou que os quarto países com mais cibercrimes eram os EUA, era de $73 \%$, na China alcançava os $83 \%$ e, no Brasil e na Índia, 76\% (NCR, 2010). Em 2007, a Forbes considerou que os quarto países com mais cibercrimes eram os EUA, China, Brasil e Rússia, nessa ordem ${ }^{7}$. Ou seja, os países BRICs compartilham a mesma forma de criminalidade, que se gerou de maneira espontânea, e sem nenhuma comunicação entre um país e outro.

3. Existe também a chamada 'economia das sombras'. As entrevistas que conduzi em Xangai em Julho de 2011 revelavam as práticas de cadeias de exportadores chineses e de importadores (brasileiros e às vezes representantes da diáspora chinesa) no Brasil, que formam redes informais de comércio e que, com a ajuda de agentes do Estado nos dois países e também no Paraguai, formam complexas redes que operam em uma escala internacional. Rosana Pinheiro Machado (2011) fez uma análise antropológica premiada dessas cadeias do Sul da China até o eixo Paraguai-Brasil. O crime organizado é também uma atividade internacionalizada, porém toca as relações entre os povos de maneiras diferentes.

\footnotetext{
Disponível em: http://www.forbes.com/2007/07/13/cybercrime-worldregions-tech-cx_ag_0716cybercrime.html.
} 
Não tenho notícias nem sobre os "desvios" de membros de outras comunidades dos países BRICS em São Paulo.

Os escritos de Sun Liping (2008) sobre a transição ajudam a entender o que está acontecendo: um exportador copia a prática de outro, bem-sucedido, e, dessa maneira, as exportações aumentam ao longo do tempo. Agentes do Estado e a iniciativa privada na China fazem parte dessa cadeia, assim como no Brasil. Parte da imigração chinesa para o Brasil é resultado dessas cadeias complexas, sendo também, em certos casos, a sua causa. A imigração ilegal emprega o método de "tentativa e erro" e também é um jogo de gato e rato; organizações patrocinam e agentes públicos brasileiros facilitam a imigração (seja com vistos concedidos em Suriname e outros países vizinhos, ou com passaportes brasileiros concedidos àqueles que nunca haviam posto os pés no país (para uma observação perspicaz, ver HAUTER, 2008: 177-8).

Tais ações, por serem classificadas como ilegais no Brasil, geram conflitos que não vazam para o espaço público, a não ser através de denúncias. De um lado, fabricantes ou importadores brasileiros, de outro lado, chineses vítimas de extorsão por agentes do Estado no Brasil.

\section{Trocas de informação}

A terceira dimensão da globalização que vou examinar são as crescentes trocas de informação, muitas vezes chamadas de "fluxos," entre os países: televisão ao vivo, cinema, artigos na imprensa, aviação, turismo, migrações, intercâmbios de vários tipos que acabam aproximando as pessoas de diferentes nacionalidades. Uma questão-chave é: como compreender e ser compreendido pelos outros? Outra questão é: como transformar os fluxos de informação - que acontecem em um mundo saturado de sinais - em comunicação? (WOLTON, 2009).

Na medida em que vivemos mais com os outros (por causa do turismo e da imigração, por exemplo), temos mais informações sobre eles. Este fato não garante que nos comuniquemos melhor 
com o outro. Ao contrário, aumenta a sensação das diferenças, acentuando possibilidades de conflito. Por essa razão, é importante refletir sobre o estatuto da informação. Fluxos de informações são retrabalhados dentro de matrizes culturais no local de recepção, processo realizado em função das qualificações, valores, gostos, interesses e orientações dos receptores, muitas vezes os primeiros receptores são "intermediários culturais" que agem de modo a filtrar e retransmitir sua versão das informações disponíveis à população, que por sua vez, reinterpreta as informações apresentadas.

\section{Migração internacional}

O estudo do fenômeno migratório é fundamental para entender as relações entre os países. Dispomos de dois estudos, um sobre chineses no Brasil e outro sobre brasileiras em Pequim-China (VÉRAS, 2008; PORTO, 2014). O Brasil recebeu grandes núm eros de migrantes russos ao longo da primeria metade do século 20, porém recebeu pouquíssimos indianos e africanos do sul.

Em relação à imigração: sabemos das centenas de gaúchos que migraram para o sul da China a fim de ensinar os chineses a fazer sapatos. Os gaúchos comemoram o carnaval, que aparece na televisão nacional. Os caracteres chineses para "carnaval" significam "dias de loucura". Dispomos de dois estudos sobre migração, um sobre as mulheres brasileiras em Pequim (PORTO, 2014) e outro no qual se demostra que a imigração chinesa ao Brasil não apenas enriqueceu a culinária, mas também contribuiu para espalhar academias de Kung Fu, a cozinha e a medicina chinesas em algumas partes do país (VÉRAS, 2008). A tese de Véras constitui uma valiosa fonte de dados e reflexão sobre a imigração chinesa no Brasil e complementa o trabalho já citado de Machado (2009).

Quando ocorrem explosões sociais, os imigrantes arriscamse a virar pólvora. Na década de 1930, casas de chineses foram queimadas no México, e o fenômeno se repetiu quando do caos que se seguiu à queda do presidente Suharto, na Indonésia, e 
na Espanha houve conflitos recentes envolvendo espanhóis e chineses. Existe uma percepção de que imigrante chinês é ilegal e se envolve com contrabando (o "maior contrabandista do país" é o título reservado para um chinês! $!^{8}$ ). No Brasil, lemos sobre tortura e assassinatos de cidadãos chineses por agentes policiais. Sabemos pouco sobre como esses eventos afetam os ânimos da comunidade de imigrantes chineses no Brasil, ou ainda como eles afetam a imagem do país na China (BIATO, 2010: 335; DGABC, 2003; BRAGA, 2008).

Considero imprescindível estudar todas as formas de conflito que envolvem turistas ou imigrantes, porque é no conflito que se revelam sentidos da ação social entre os dois povos.

\section{Intercâmbio de Informações - O Exemplo da Cooperação Científica}

O intercâmbio de informações acontece em um grande número de áreas. Aqui vou tratar só uma destas áreas aquela que é para nós, pesquisadores, uma área de intercâmbio vital - a cooperação científica. Fornecerei algumas informações a respeito, antes de especular sobre o futuro da sociologia brasileira.

A cooperação científica bilateral do Brasil, tanto com a Rússia como com a China, vem crescendo desde o final do regime militar. A cooperação científica com a Rússia é regulada por uma declaração conjunta dos Ministérios de Relação Exteriores de ambos os países, assinada em 1997, concentrada no uso pacífico do espaço, da energia, da tecnologia militar, e uma área de alcance que é tanto tecnológica quanto científica.

Atualmente, a cooperação bilateral com a China gira em torno dos biocombustíveis e da agricultura, e acordos foram assinados em diversas áreas como: engenharia florestal, hidroelétricas, materiais novos e engenharia biológica; e acordos

8 Cf. <http://noticias.uol.com.br/ultnot/efe/2004/06/01/ult1807u6326.jhtm>. Acesso em: 7 de maio de 2011. 
foram igualmente assinados nas áreas de saúde e energia nuclear. Porém, a mais importante e duradoura das cooperações com a China tem sido na área do programa aeroespacial, iniciado na década de 1980, que resultou no lançamento do primeiro satélite no programa China-Brazil Earth Resources Satellite (CBERS) em 1999, e outros após esse.

No ano de 2003, o Ministério de Ciência e Tecnologia da Índia assinou um acordo de cooperação com o Conselho Nacional de Desenvolvimento Científico e Tecnológico (CNPq) contemplando principalmente as áreas de biotecnologia, oceanologia, materiais e tecnologias de construção, e metrologia.

Durante o regime militar, o Brasil travou contatos secretos com a África do Sul, em torno de uma possível cooperação nuclear ${ }^{9}$ Mais recentemente, a "Declaração de Brasília" identificou a área de Ciência e Tecnologia como uma das principais áreas para incrementar tanto a interação como a cooperação trilateral, e sua implementação deve ser guiada pelos ministérios da Ciência e Tecnologia da Î́ndia, do Brasil e da África do Sul (IBSA) por meio de encontros anuais com o objetivo de estabelecer modalidades de cooperação, identificando áreas. Temos, portanto, uma agenda de pesquisa que poderia ser absorvida pela sociologia da ciência, que envolve a reconstrução da história dos acordos entre nossos países, a comparação com acordos feitos com os países desenvolvidos, a avaliação dos casos de sucesso, assim como dos conflitos surgidos nos processos de cooperação. Tendo em vista que, em teoria, a atividade científica não seja dominada pelos interesses comerciais, seria interessante estudar as barreiras de comunicação entre cientistas engajados em acordos de cooperação científica para aprendermos sob quais condições e sob quais circunstancias relações de confiança são construídas. Tais pesquisas, situadas no escopo da "sociologia dos BRICS", poderiam contribuir para futuras gerações nas áreas de ciências, negócios e governança, uma

\footnotetext{
Disponível em: http://www.wilsoncenter.org/publication/brazil-southafrica-nuclear-relations. Acesso em: 3 mai. 2014.
} 
vez que ofereceriam um aprendizado acerca dos sucessos, erros e limites encontrados no passado.

Porém, sabemos que o campo das ciências é dominado por relações de poder. Ao olhar para o passado e examinar a agenda de cooperação científica entre os BRICS, vemos que o governo brasileiro não apresentou grandes esforços para apoiar pesquisas relacionadas às ciências sociais. Tendo em vista que a globalização é um processo que inclui, também, a esfera cultural, uma vez que o desenvolvimento tecnológico e científico é entrelaçado à cultura, aos valores e à mudança social, esta falta de apoio aparece como um extraordinário silêncio. O ônus deve ser assumido por nós, cientistas sociais. Precisamos convencer aqueles no poder de que temos algo a contribuir.

\section{Intercâmbio científico - Passos concretos na criação de uma Sociologia nos/dos BRICS}

Até recentemente, o intercâmbio entre cientistas sociais dos nossos países era extremamente limitado. No congresso da SBS, em 2007, na cidade de Recife, houve uma mesa redonda sobre os BRICS, para a qual foram convidados representantes do Brasil, Rússia, China e África do Sul. Neste encontro, travou-se uma troca interessante sobre dados sincrônicos e diacrônicos de cada país, com ênfase tanto na dimensão qualitativa quanto na quantitativa, empregando conceitos sociológicos, demográficos e políticos para transmitir informações básicas necessárias para dar início a comparações entre os países. Uma das apresentações ressaltou o aumento do intercâmbio entre os cinco países e foi sugerido que tais intercâmbios seriam um espaço fértil de pesquisa. A discussão não apenas provocou o público a pensar sobre o Brasil com novas fontes de referência, mas também sugeriu novos objetos de estudo.

No ano de 2009, o então presidente da Sociedade Chinesa de Sociologia, Li Peilin, ministrou uma palestra na conferência da SBS no Rio de Janeiro (LI e LI, 2011); ele também visitou o IBGE e o IPEA e se convenceu de que uma pesquisa comparativa entre o 
Brasil e a China poderia enriquecer a Sociologia chinesa com novas perspectivas. Desde 2004, sigo convicto de que é necessário abrir a sociologia brasileira para a China. O nível técnico das pesquisas sociológica chinesas é muito alto. Porém, é necessário prestar muita atenção ao fato de que os contextos, perspectivas e sistemas de relações sociais e políticas centrais são muito diversos - a China não é um país para amadores! Mas minha aposta era no caráter fundamental da construção de um diálogo científico bilateral entre a China e o Brasil. Nenhum país do mundo hoje pode se permitir a desconhecer a China, a sociologia brasileira não poderia pensar processos globais sem incorporar conhecimento sobre o país que passaria a ser nosso maior parceiro comercial.

A atenção crescente dada aos BRICS insere o diálogo BrasilChina dentro de um campo comunicacional muito mais complexo. Em 2013, sociólogos da China, Índia e África do Sul vieram à Unicamp, e depois foram ao Congresso da SBS em Salvador para discutir o conteúdo e encaminhamento de um livro e outras publicações sobre "sociologia da juventude nos países BRICS". Os resultados deste diálogo serão publicados em breve.

\section{Estratificação Social nos países BRIC}

Em julho de 2010, as associações de sociologia dos países BRIC realizaram uma sessão integrada no Congresso Mundial de Sociologia da International Sociological Association (ISA) em Gotemburgo, na Suécia. O resultado foi um engajamento de pesquisadores em uma agenda baseada no segundo item apresentado acima. Pouco mais de um ano depois, em Outubro de 2011, o primeiro fruto desse encontro amadureceu: um livro sobre estratificação social nos países BRIC foi publicado com o título de Jin Zhuan Guo Jia She Hui Fen Ceng: Bian Qian Yu Bi Jiao. A CASS organizou um fórum para discutir o conteúdo e para desenvolver planos para o futuro; Celi Scalon, presidente da SBS e organizadora da contribuição brasileira, liderou uma delegação de seis brasileiros, e uma delegação russa do mesmo tamanho 
também estava presente. $\mathrm{O}$ livro de mais de 800 páginas na sua versão em língua inglêsa compreende um estudo comparativo de estratificação social nos países BRIC, e Li Peilin escreveu, em sua introdução:

A razão pela qual estou disposto a desprender tempo e energia organizando este livro comparativo sobre as estruturas sociais nos países BRIC, e na expansão da pesquisa comparativa Sino-Russa para um projeto comparativo muito maior entre os quatro países BRIC, é porque eu realmente acredito que este livro será de grande influência após sua publicação. Esta influência não é somente resultado do conteúdo dos artigos, mas também é fruto do impacto da ascendência dos BRIC na economia e política globais.... a análise de mudanças sociais estruturais, especialmente das mudanças nas estruturas de estratificação social dos países BRIC, é uma perspectiva sociológica única no estudo e na análise de questões sociais. Esta perspectiva única nos ajudaria a alcançar um maior entendimento do crescimento econômico e do desenvolvimento social nas potencias econômicas emergentes. Esta perspectiva especial também nos ajudaria a desvendar o mistério de como estas potencias emergentes, tão distintas em termos de história, geografia, cultura, língua, religião, etc., poderiam compartilhar objetivos em comum e poderiam agir em conjunto sob certas circunstancias. De qualquer forma, são exatamente estas mudanças profundas nas estruturas sociais que determinarão o futuro destes países e que, ademais, irão moldar a paisagem socioeconômica do mundo no futuro (LI et ali, 2011).

Em 2013, o livro foi publicado em inglês pela World Scientific Publishing Co. de Cingapura sob o título de Handbook of Social Stratification in the BRIC Countries (LI et alii, 2013). Toda essa iniciativa foi "autogerida", uma vez que representantes de cada associação de sociologia dos quatro países BRIC organizaram a contribuição de autores especialistas, com recursos financeiros 
limitados e sem que nenhum contrato de pesquisa ou convênio fosse assinado. No lançamento do livro em Pequim, no ano de 2011, pesquisadores acordaram em avançar a pesquisa com um segundo projeto (já mencionado) que corresponde ao terceiro item sugerido na reunião de Pequim em 2010: “a sociologia da juventude nos países BRIC".

\section{Entender os BRICS}

O Brasil e os outros países BRICS estão desenvolvendo rapidamente relações de comércio, relações supranacionais e de trocas de informação, e, com isso, podemos prever a necessidade de travarmos um entendimento mútuo entre as nações, especialmente ao enfrentarmos a realidade de que inúmeros conflitos podem surgir como produto destas relações. Nós simplesmente sabemos muito pouco sobre eles, assim como eles sabem muito pouco sobre nós. Temos exemplos, do passado, de esforços para uma possível cooperação, que servem de material para uma reflexão sociológica acerca das interações, no passado e no presente, entre os países. Se os BRICS pretendem de fato se estabelecer enquanto uma associação de potências no cenário mundial, precisarão se apoiar nas suas populações, na sua relevância econômica e geográfica, no diálogo e no mútuo entendimento.

No campo da sociologia internacional, o impacto do reconhecimento da sociologia dos/nos BRICS a longo prazo depende da ambição teórica e da capacidade de ajudar a interpretar o mundo - e nossas interações - de uma outra maneira. Ao conhecermos melhor os trabalhos dos sociólogos dos outros países, ao entendermos melhor os processos sociais em curso nos outros países, propostas de pesquisas devem surgir, permitindonos a produção de conhecimento com novas ambições teóricas.

Igualmente, será preciso formar alunos capazes de montar o quebra-cabeça das ciências sociais em construção nos/dos BRICS e, com isso, elaborar teoria. Penso que existe uma alta probabilidade de inovação entre uma nova geração de pesquisadores bilíngue 
(ou mesmo poliglota), de tradutores e intérpretes especializados em ciências sociais e nas culturas e nas línguas nativas dos BRICS. A civilização brasileira (RIBEIRO, 1995) é uma tese bem conhecida dos leitores brasileiros. É interessante observar que, na tese de doutorado de Véras sobre migração chinesa ao Brasil, um dos entrevistados raciocinava a partir da ideia do que o Brasil representa uma nova civilização ainda em fase de maturação:

Então o fato de o Brasil ser um país com várias etnias diferentes, e com uma história relativamente curta... se temos 500 anos de história, eu vivi $10 \%$ dessa história.... Então me permite ter uma visão bastante objetiva, não tanto subjetiva, do país... Eu acho que o país está evoluindo, eu acho que o país vai levar mais três ou quatro gerações para ser um país realmente [...] um país com sua identidade, com suas regras muito bem definidas (VÉRAS, 2008: 199).

\section{Além de uma Sociologia dos BRICS - uma hipótese russa}

No encontro anual da ANPOCS, em 2013, foram organizadas seis mesas redondas sobre as Ciências Sociais nos países BRICS. Os participantes apresentam interpretações sobre processos em curso em seus próprios países, com referências específicas em: desenvolvimento, políticas públicas, justiça social, inclusão social, poderes emergentes e transformações no sistema internacional. $\mathrm{O}$ que houve foi uma salutar abertura interdisciplinar, que aproximou cientistas sociais dos cinco países, propondo uma série de discussões de interesse comum a todos, e a criação de uma base para cooperação no futuro. Porém, existe uma outra possibilidade, fornecida pela estimulante reflexão de Boris F. Martynov, vice diretor do Latin American Institute da Academia de Ciências Russas, sobre o papel dos países BRICS numa ordem mundial em degradação. “China, Índia, Brasil, Rússia e, em menor grau a África do Sul, são detentores de enormes territórios, numerosas populações, economias significativas e potências energéticos e 
ecológicos extensas. Demostram uma grande influência cultural e civilizacional sobre países vizinhos e regiões conexas. Falando sobre tal influência, vale assinalar que civilizações não dizem respeito apenas à economia e à política, mas o que atua na formação de realidades globais mediante a política e a economia. Isso é cultura. É nosso arcabouço cultural que se pode descobrir mais semelhanças entre a 'grande China', a 'grande Rússia', a 'grande Índia' e o 'grande Brasil' este último e seu entorno latinoamericano, do que entre a China, o Brasil, a índia e a Rússia, como Estados nacionais com seus interesses, amiúde contraditórios. Vale a pena, ao nosso ver, falar não em 'países gigantes emergentes', mas em 'civilizações emergentes' do mundo contemporâneo, que eles representam. Justamente esta caraterística diferencia de uma maneira peculiar os BRICs do assim chamado 'segundo escalão' dos estados emergentes, como o México, e o Paquistão, a Indonésia e outros, cuja ascensão potencial não afetará de forma substancial a textura política mundial" (MARTYNOV, 2009: 89-90).

Martynov, então, extrapolou bastante a ideia original de O'Neill. O conceito BRIC agora é visto a partir de um significado também cultural.

Poderia considerar-se em relação a isso que para os BRIC, enquanto 'civilizações ascendentes', é inerente uma busca comum, talvez intuitivo, por um modelo alternativo de desenvolvimento, fundamentado na afirmação de uma multipolaridade na política global, no equilíbrio na economia e comercio e nas tentativas de aplicação dos elementos de justiça social na política doméstica. Parece que a conjuntura econômica e a política global contribuem cada vez mais para alcançar esses objetivos.... De acordo com essa ideia, uma sinergia civilizacional, ou seja, uma fusão do público e do privado, do visionário e do pragmático, dentro da visão de 'entusiastas dos BRICs', é capaz de criar o mundo uma consciência criativa que impulsionaria os países gigantes a ocuparem a vanguarda de mudanças maduras e ajudá-los a ocuparem posições mais 
notáveis no areópago mundial (MARTYNOV, 2009:

91).

No fim de seu ensaio de rara perspicácia, o autor olha para o futuro mencionando (entre outros) dois vetores em torno dos quais os BRICs poderiam se unir:
a certeza gradualmente acumulada da imprescindibilidade de se reconsiderar a base valorativa da existência humana em detrimento do ilimitado consumismo, extremo individualismo e moralismo relativista e... orientação fundamental para a criação de uma nova cultura global, pela qual se dá mais valor ao ambientalismo, ao coletivismo e a espiritualidade (MART-NOV, 2009: 103).

Ao que acrescentarei a ideia compartilhada por sociólogos nos países BRICS, e muito explícita no diálogo China-Brasil, sobre a necessidade de questionar as desigualdades sociais e seus efeitos negativos sobre o desenvolvimento humano e social.

E, dentro deste enorme desafio intelectual, sociólogos e outros devem buscar, onde quer que estejam, pensar os patamares de suas disciplinas. Importante é organizar agendas de pesquisas comparativas, assim como intercâmbios científicos significativos, e construir um amplo diálogo interdisciplinar com todos os setores, para responder a necessidade de dar inteligibilidade e sermos, como nação, capazes de confrontar os mais importantes desafios intelectuais impostos pela ascendência dos BRICS - e desenvolver uma resposta - na prática e na teoria - à pergunta: como viver juntos?

\section{References}

ABRAMOVAY, R. Paradigmas do capitalismo agrário em questão. São Paulo: Hucitec, 1992. 
ARRIGHI, G. Adam Smith em Pequim - origens e fundamentos do século XXI. São Paulo: Boitempo, 2008.

BIATO JUNIOR, O. A Parceria Estratégica Sino-Brasileira: origens e perspectivas (1993-2006). Brasília: Fundação Alexandre de Gusmão, 2010.

BRAGA, R. "Quatro policiais presos por morte de comerciante chinesa". O Globo $30 / 10 / 2008$, p. 1B.

BURAWOY, M. "Facing an Unequal World: Challenges for a Global Sociology" In: BURAWOY, M.; CHANG, Mau-kuei; HSIEH, Michelle Fei-yu. (Org.). Facing an Unequal World: Challenges for a Global Sociology. Taipei: Institute of Sociology, Academia Sinica Council of National Associations of the International Sociological Association. v. 1, 2010, p. 3-27.

DGABC. "Polícia pede prisão de agentes acusados da morte de chinês". Diário do Grande ABC, São Paulo, 06/09/2003. Disponível em: <www.achanoticias.com.br/noticia_pdf. kmf?noticia=1255614>. Acesso em: 7 mai. 2011.

DWYER, T. 2011. Relations between the BRICS: A Reflection from a Brazilian Sociological Viewpoint. Fudan Journal of the Humanities and Social Sciences. Vol. 4, n. 4, pp. 27-55.

FREYRE, G. China Tropical. São Paulo e Brasília: Imprensa Oficial do Estado e Editora da Universidade de Brasília, 2003.

GIDDENS, A. As Conseqüências da Modernidade. São Paulo: Editora UNESP, 1991.

GLENNY, M. McMafia: A journey through the global criminal underworld. New York: Vintage Books, 2009.

HAUTER, F. Planète chinoise. Paris: Carnets Nord, 2008.

LAPA, J. R. do A. A Bahia e a Carreira da Índia. São Paulo: Editora da Universidade de São Paulo e Companhia Editora Nacional, 1968. 
LEITE, J. R. T. A China no Brasil: Influências, marcas, ecose sobrevizências chinesas na sociedade e na arte brasileiras. Campinas: Editora da Unicamp, 1999.

IANNI, O. "A Sociologia numa época de globalismo". In: FERREIRA, L. (org.) A Sociologia no horizonte do século XXI. São Paulo: Boitempo, 1997.

LI, P. e LI, W. "O status econômico e as atitudes sociais dos trabalhadores migrantes na China", In DWYER, T. et al (orgs).

Consensos e Controvérsias. Porto Alegre: Sociedade Brasileira de Sociologia e Tomo Editorial, 2011, p. 31-49.

LI, P.; SCALON, C.; GORSHKOV, M. K.; SHARMA, K. et al (orgs). Jin Zhuan Guo Jia She Hui Fen Ceng: Bian Qian Yu Bi Jiao. Pequim: Chinese Academy of Social Sciences, 2011.

LI, P.; SCALON, C.; GORSHKOV, M. K.; SHARMA, K. (orgs). Handbook of Social Stratification in the BRICs countries. Singapore: World Scientific Publishing, 2013.

MACHADO, R. P. Made in China: produção e circulação de mercadorias no circuito China-Paraguai-Brasil. São Paulo: Editora Hucitec, 2011.

MARTYNOV, B. F. "Os BRICs e a ordem mundial em degradação”. In ZHEBIT, A., 2009, pp. 83-103

NCR. Norton Cybercrime Report-The Human Impact. 2010. Disponível em: http://us.norton.com/theme.jsp?themeid=cybercrime_ report. Acesso em: 29 jan. 2012.

PATEL, S. "Para além de um pensamento binário: Questões para uma Sociologia auto-reflexiva", in PORTO, M. S. G.; DWYER, T. Sociologia e Realidade: Pesquisa social no Século XXI. Brasília: Editora da UnB, 2006, p. 37-50.

PORTO, A. C. P. Chega de Samba: Estratégias de recriação da identidade pelas brasileiras em Pequim. 2014. Tese. Programa de Pósgraduação em Sociologia, Universidade Federal da Paraíba, João Pessoa. 
RIBEIRO, D. O Povo Brasileiro: A formação e o sentido do Brasil. São Paulo: Companhia das Letras, 1995.

SANTOS, B. S. A Globalização e as Ciências Sociais. São Paulo: Cortez Editora, 2005.

SUN, L. "Societal Transition: New issues in the field of the sociology of development". Modern China, vol. 34, no. 1, 2008a, pp. 88113.

TYURDENEV, V. "Palavra do embaixador da Rússia no Brasil Vladimir Tyurdenev". In: ZHEBITt, A. (org), 2009, p. V-VIII.

WIEVIORKA, M. Neuf leçons de sociologie. Paris: Robert Laffont. Chapter 2, 2008.

WOLTON, D. Informer n'est pas communiquer. Paris: CNRS Editions, 2009.

ZHEBIT, A. (org). Brasil-Rússia: História, política, cultura. Rio de Janeiro: Gramma, 2009. . (org.). Brasil-China: construindo os BRICS. Rio de Janeiro: Editora da UFRJ, 2013.

Recebido em 09/06/14.

Aprovado em 14/07/14. 
